\title{
Molecular and Haematological Characteristics of alpha-Thalassemia Deletions in Yogyakarta Special Region, Indonesia
}

\author{
Nailil Husna ${ }^{1}$, Niken Satuti Nur Handayani*1
}

\begin{abstract}
Background: alpha-Thalassemia is caused primarily by deletions of one to two alpha-globin genes and is characterized by absent or deficient production of alpha-globin protein. The South-East Asia (SEA) deletion, 3.7-kb and 4.2-kb deletions are the most common causes. The present study aimed to observe the molecular characteristics of this common alpha-Thalassemia deletions and analyse its haematological parameter.

Methods: Blood samples from 173 healthy volunteers from thalassemia carrier screening in Yogyakarta Special Region were used. Haematological parameters were analysed and used to predict the carrier subjects. Genotype of suspected carriers was determined using multiplex gap-polymerase chain reaction and its haematological parameters were compared. The boundary site of each deletion was determined by analysing the DNA sequences.

Results: Seventeen (9.8\%) of the volunteers were confirmed to have alpha-Thalassemia trait. Of these, four genotypes were identified namely $-\alpha^{3.7} / \alpha \alpha(58.8 \%),-\alpha^{4.2} / \alpha \alpha(5.9 \%),-\alpha^{3.7} /-\alpha^{4.2}(5.9 \%)$ and $--^{\mathrm{SEA}} / \alpha \alpha(29.4 \%)$. The $5^{\prime}$ and $3^{\prime}$ breakpoints of SEA deletion were located at nt165396 and nt184700 of chromosome 16, respectively. The breakpoint regions of 3.7-kb deletion were 176-bp long, whereas for 4.2-kb deletion were 321-bp long. The haematological comparison between normal and those with alpha-Thalassemia trait genotype indicated a significant difference in mean corpuscular volume $(\mathrm{MCV})(\mathrm{p}<0.001)$ and mean corpuscular haemoglobin $(\mathrm{MCH})(\mathrm{p}<0.001)$. As for identifying the number of defective genes, $\mathrm{MCH}$ parameter was more reliable $(\mathrm{p}=0.003)$.
\end{abstract}

Conclusions: The resultant molecular and haematological features provide insight and direction for future thalassemia screening program in the region.

Keywords: Allelic Imbalance, Alpha-Thalassemia, Indonesia, Multiplex Polymerase Chain Reaction, Sequence Deletion.

\section{Introduction}

alpha-Thalassemia is a hereditary disorder of blood that results in absence or deficiency in the synthesis of alpha-globin chains. It is caused by mutation on alpha-globin (HBA1 and HBA2) genes or deletion of alpha-globin gene cluster. Since there are two sets of HBA in human genome, alpha-Thalassemia have more genotype variety in its carrier form employing one to two altered or deleted genes. The syndrome occurs at high frequencies throughout tropical and subtropical regions of the world, including Southeast Asian countries (1-3).

In Indonesia, alpha-Thalassemia cases has been widely reported (4-7). However, a study that specifically discussed about its molecular characteristics such as breakpoint site of deletions is still limited. Furthermore, a study that reported haematological comparison of different carrier form is also absent. Therefore, this study aimed to report the molecular 
characteristics of three common alphaThalassemia deletion namely South-East Asia (SEA), 3.7-kb and 4.2-kb deletions, and analyse the different in its haematological parameter.

\section{Materials and Methods \\ Study subjects}

The subjects were 173 unrelated healthy individuals who voluntarily underwent thalassemia screening organized by the Indonesian Association of Parents of Children with Thalassemia (APCT) Yogyakarta, the Indonesia Thalassemia Foundation (ITF) and in collaboration with Faculty of Biology, Universitas Gadjah Mada. The obtained blood samples were measured for haematological parameters. Samples with a mean corpuscular haemoglobin $(\mathrm{MCH})$ level and a mean corpuscular volume (MCV) level of $\leq 27 \mathrm{pg}$ and $<80 \mathrm{fL}$, respectively, were suspected as alpha-Thalassemia carrier.

\section{Genotype determination}

Seventeen samples were suspected as alphaThalassemia carrier. Its genomic DNA was isolated from peripheral blood leukocytes with the Genomic DNA mini kit for blood and tissues (Geneaid, Taipei, Taiwan). The molecular investigation was performed with polymerase chain reaction (PCR). The gapPCR with the multiplex reaction method (8) was modified to detect only three deletions. Primers to detect the SEA, 3.7-kb, and 4.2-kb deletions, as well as the a2 gene were used. As the control for the reaction, we used the product of forward-primer of SEA and a new reverse-primer named SEA-N (5'TGAAGAGCCTGCAGGACCAGG-3' (reverse) which also simultaneously served as negative control for SEA deletion. This control PCR product is located upstream of alpha-globin gene cluster between HBZP1 and HBM along 1019-bp.

The reaction mixture contained $12.5 \mu \mathrm{L}$ KAPA Taq Extra HotStart ready mix (KAPABiosystems Massachusetts, USA), 50-150 ng genomic DNA, and eight different primers at concentrations of $0.2 \mu \mathrm{M}$, except
SEA-F and a2/3.7-F, which were $0.4 \mu \mathrm{M}$. The reactions were performed in the ProFlex PCR System (Applied Biosystems, Foster City, CA, USA), with an initial three min denaturation at $95{ }^{\circ} \mathrm{C}$, followed by 40 cycles of $98{ }^{\circ} \mathrm{C}$ denaturation for $30 \mathrm{sec}, 62{ }^{\circ} \mathrm{C}$ annealing for $60 \mathrm{sec}$, and a $72{ }^{\circ} \mathrm{C}$ extension for $135 \mathrm{sec}$, followed by a final $5 \mathrm{~min}$ extension at $72{ }^{\circ} \mathrm{C}$. Five $\mu \mathrm{L}$ of each amplified product was used for $2 \%$ agarose gel electrophoresis in $1 \times$ Tris-Borate-EDTA buffer at $50 \mathrm{~V}$ for 1 hour. The gel was viewed under UV transilluminator and then documented.

\section{DNA Sequence analysis}

The PCR products that covered junction region of each deletion was amplified with single reaction PCR. Then, the bands were sequenced with Sanger methods by DNA Sequencing Services (1st BASE, Selangor, Malaysia). The sequences were analysed and aligned using the ClustalW with the reference sequence from NCBI (RefSeq NC_000016.10) to determine the breakpoint site for each deletion type.

\section{Haematological data analysis}

First, haematological parameters (Haemoglobin, MCV and $\mathrm{MCH}$ ) of normal samples and samples that suspected as alphaThalassemia carrier were analysed using student's $t$ test. Then, employing the genotyping result, carrier samples were divided into silent trait with a single alphaglobin gene deletion and trait with two genes deletion. Haematological parameters of these two groups were also analysed with student's t test.

\section{Ethical consideration}

The study was reviewed and approved by the Medical and Health Research Ethics Committee (MHREC), Faculty of Medicine, Public Health and Nursing, Universitas Gadjah Mada-Dr. Sardjito General Hospital (Ref. No.: $\mathrm{KE} / \mathrm{FK} / 1320 / \mathrm{EC} / 2019)$. Informed consents were received from each volunteer. The confidentiality of collected and retrieved data are ensured. 


\section{Results}

Among the 173 volunteers, 17 (9.8\%) were predicted to be carrier for alpha-Thalassemia based on the haematological parameters. A comparison of the haematological parameters between the normal and carrier groups was summarized in Table 1 . The comparison showed a significant difference $(\mathrm{p}<0.005)$ in $\mathrm{MCV}, \mathrm{MCH}$, and haemoglobin in females.

Table 1. Hematological comparison of suspected alpha-thalassemia carrier and normal group.

\begin{tabular}{|c|c|c|c|c|c|c|}
\hline \multirow{3}{*}{ Group } & \multirow{2}{*}{\multicolumn{2}{|c|}{$\mathbf{n}$}} & \multicolumn{4}{|c|}{ Hematological Parameter } \\
\hline & & & \multicolumn{2}{|c|}{$\mathrm{Hb}(\mathrm{g} / \mathrm{dL})$} & \multirow{2}{*}{ MCV (fL) } & \multirow{2}{*}{ MCH (pg) } \\
\hline & $\mathbf{M}$ & $\mathbf{F}$ & $\mathbf{M}$ & $\mathbf{F}$ & & \\
\hline Normal & 59 & 97 & $15.17 \pm 1.32$ & $13.12 \pm 1.00$ & $85.50 \pm 4.16$ & $29.04 \pm 3.09$ \\
\hline $\begin{array}{l}\text { alpha-thalassemia } \\
\text { carrier }\end{array}$ & 6 & 11 & $13.62 \pm 1.57$ & $11.42 \pm 1.68$ & $72.55 \pm 6.50$ & $23.21 \pm 2.22$ \\
\hline p-value* & & & $\mathrm{p}=0.03$ & $\mathrm{p}=0.004$ & $\mathrm{p}<0.001$ & $\mathrm{p}<0.001$ \\
\hline
\end{tabular}

*p-values from Student's $t$-test for independent samples

Based on the molecular investigation shown in Figure 1, samples were divided into four genotype which were $-\alpha^{3.7} / \alpha \alpha$ $(58.8 \%),-\alpha^{4.2} / \alpha \alpha(5.9 \%),-\alpha^{3.7} /-\alpha^{4.2}(5.9 \%)$ and --
$\mathrm{SEA} / \alpha \alpha$ (29.4\%). Among them, $-\alpha^{3.7}$ allele showed the highest prevalence appearing in 11 subjects or comprised $64.7 \%$ of the cases (Table 2).

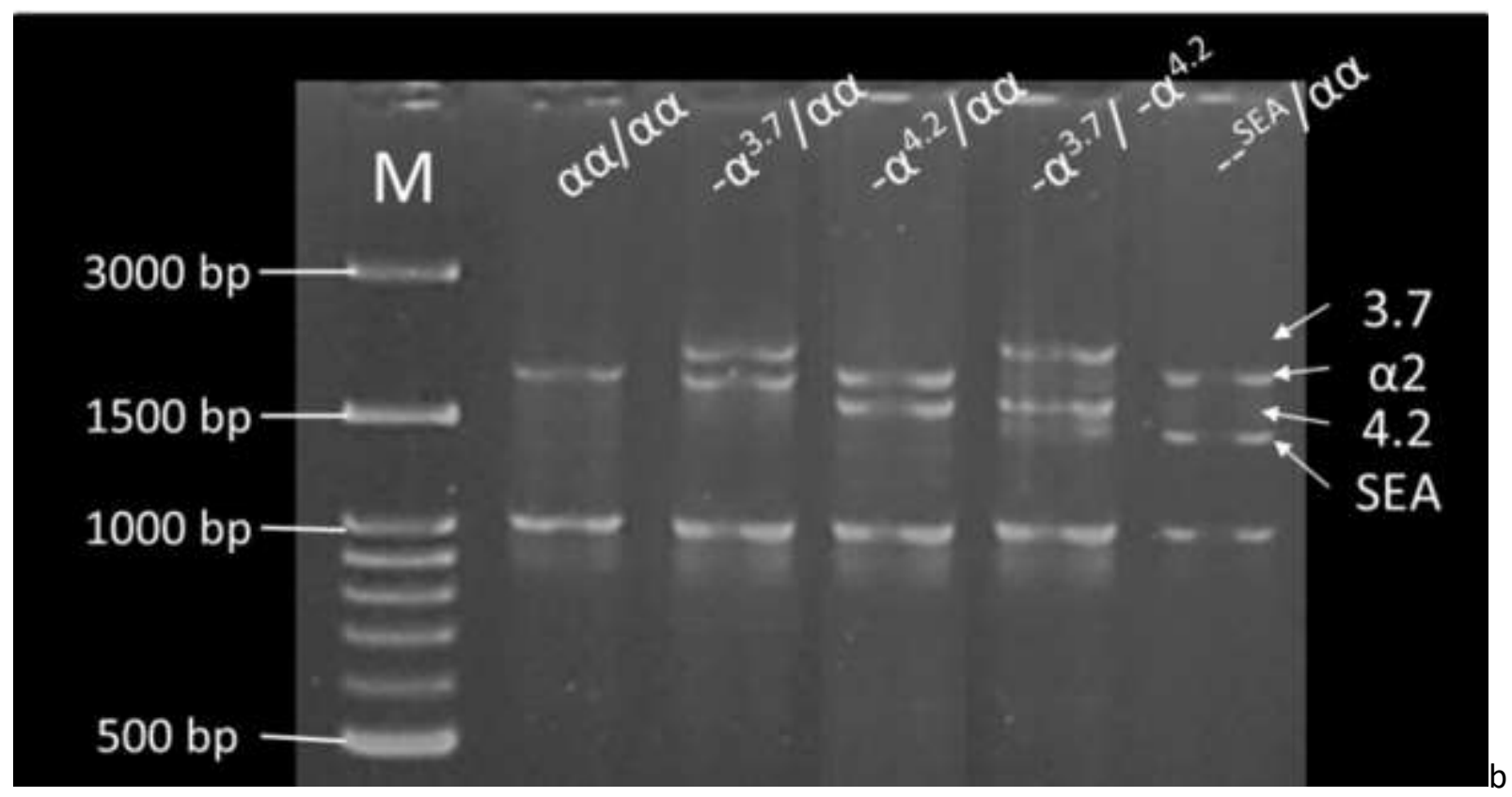

Fig. 1. DNA samples with five alpha-globin genotypes, M; marker.

DNA sequencing of the - SEA allele (Fig. 2) showed that the $5^{\prime}$ breakpoint location was upstream of the alpha-globin gene cluster between HBZP1 ( $\Psi \zeta 1$ gene) and HBM ( $\Psi \alpha 2$ gene), 191-bp after the end of the HBZP1 sequence. The $3^{\prime}$ breakpoint was located downstream of the alpha-globin cluster, 3521-bp after the end of HBQ1 ( $\theta 1$ gene). The complete sequence has been submitted to NCBI nucleotide database under accession number MN562876. The template used for this alignment was NCBI RefSeq NC_000016.10 nt163067-nt181179.

Figure 3 showed sequence analysis of $-\alpha^{3.7}$ and $-\alpha^{4.2}$ alleles. Both sequences were aligned with the homology boxes resulting in a breakpoint range, $\mathrm{Z}$ homology box for $-\alpha^{3.7}$ allele 
and $\mathrm{X}$ homology box for $-\alpha^{4.2}$ alleles. The template used for this alignment was NCBI RefSeq NC_000016.10 nt169268-nt177719.

Table 2. Genotype distribution of alpha-thalassemia trait.

\begin{tabular}{rl}
\hline Genotype & $\mathrm{n}$ \\
\hline Silent trait & \\
$\bullet \quad-\alpha^{3.7} / \alpha \alpha$ & 10 \\
$\bullet-\alpha^{4.2} / \alpha \alpha$ & 1 \\
Trait & \\
$\bullet \quad-\alpha^{3.71}-\alpha^{4.2}$ & 1 \\
$\bullet \quad--{ }^{S E A} / \alpha \alpha$ & 5 \\
\hline
\end{tabular}

In $-\alpha^{3.7}$ allele, the $5^{\prime}$ breakpoint region of $\mathrm{Z} 2$ box ranged at nt172241 to nt172417, whereas the $3^{\prime}$ breakpoint of $\mathrm{Z1}$ box ranged at nt176044 to nt176220. The breakpoint regions of 3.7-kb deletion were 176-bp long (Fig. 3B). The deletion caused approximately 3804-bp loss including complete gene of HBA1. Similarly, in the $-\alpha^{4.2}$ allele, HBA2 was also absent due to a loss of approximately 4257-bp. The 5' breakpoint region of X2 box ranged at nt169498 to nt169819, whereas the $3^{\prime}$ breakpoint of X1 box ranged at nt173755 to nt174076 (Fig. 3C). The breakpoint regions of $4.2-\mathrm{kb}$ deletion were 321-bp long.

A

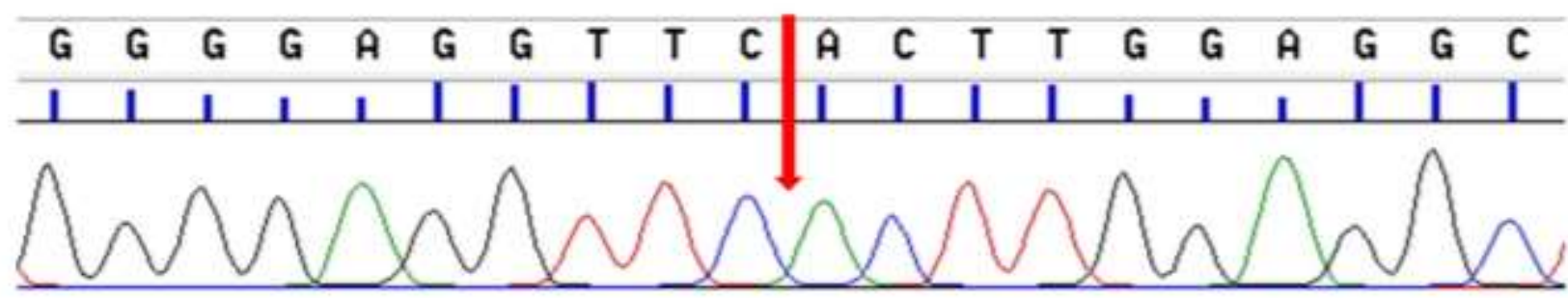

B

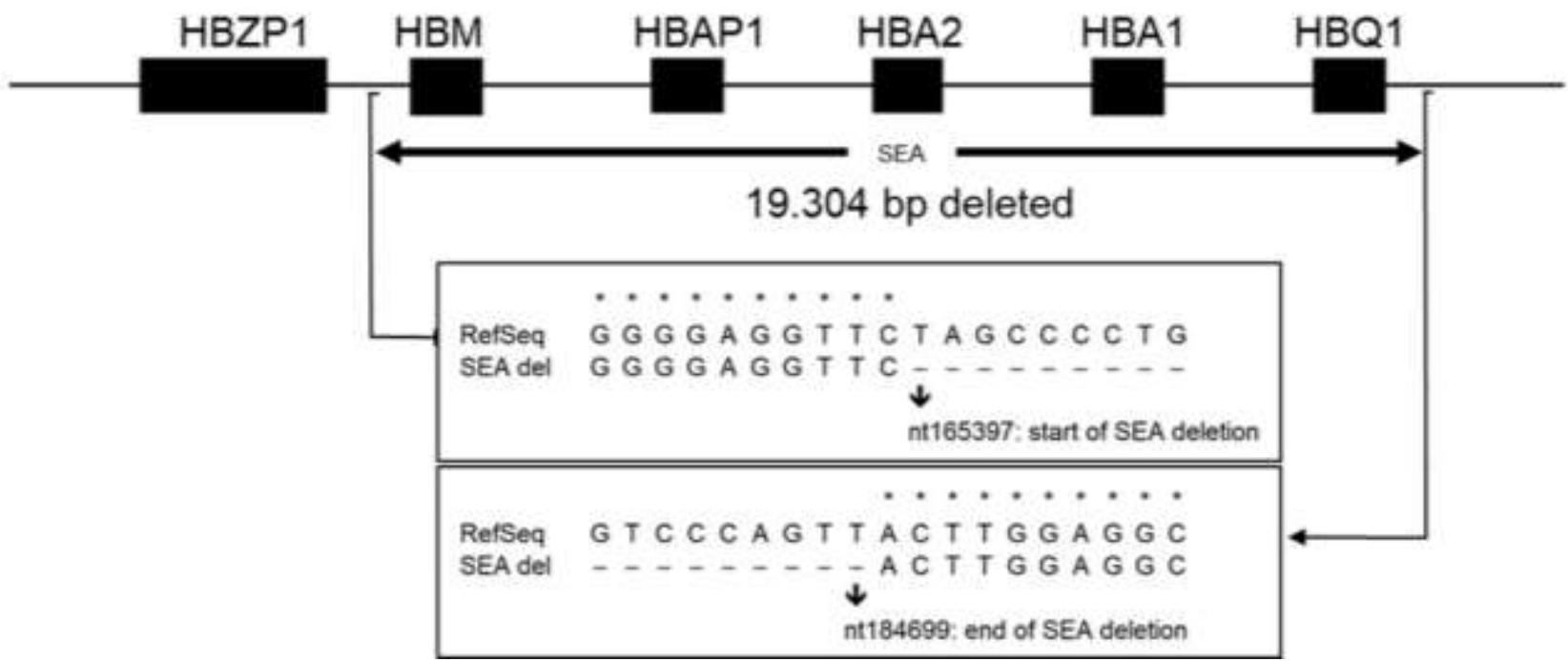

Fig. 2. The DNA sequence of SEA deletion boundaries (A) Chromatogram shows the breakpoint site, (B) DNA sequence shows the $5^{\prime}$ and $3^{\prime}$ breakpoints at nt165396 and nt184700 of chromosome 16 respectively, producing 19.304-bp of deletions.

Although these deletions caused a fusion of affected homology boxes, it gave no effect on the remaining genes because its breakpoint regions are outside of the genes. The complete sequences have also been submitted to NCBI nucleotide database under accession number MN562877 and MN562878 for 3.7-kb deletion and $4.2-\mathrm{kb}$ deletion, respectively.
Lastly, a comparison of haematological parameters of genotype group was conducted. The genotypes of silent trait group were $\alpha^{3.7} / \alpha \alpha$ and $-\alpha^{4.2} / \alpha \alpha$, while genotypes of trait group were $-\alpha^{3.7} /-\alpha^{4.2}$ and $-{ }^{\mathrm{SEA}} / \alpha \alpha$. The comparison showed a significant difference in $\operatorname{MCH}(\mathrm{p}=0.003)($ Table 3$)$. 


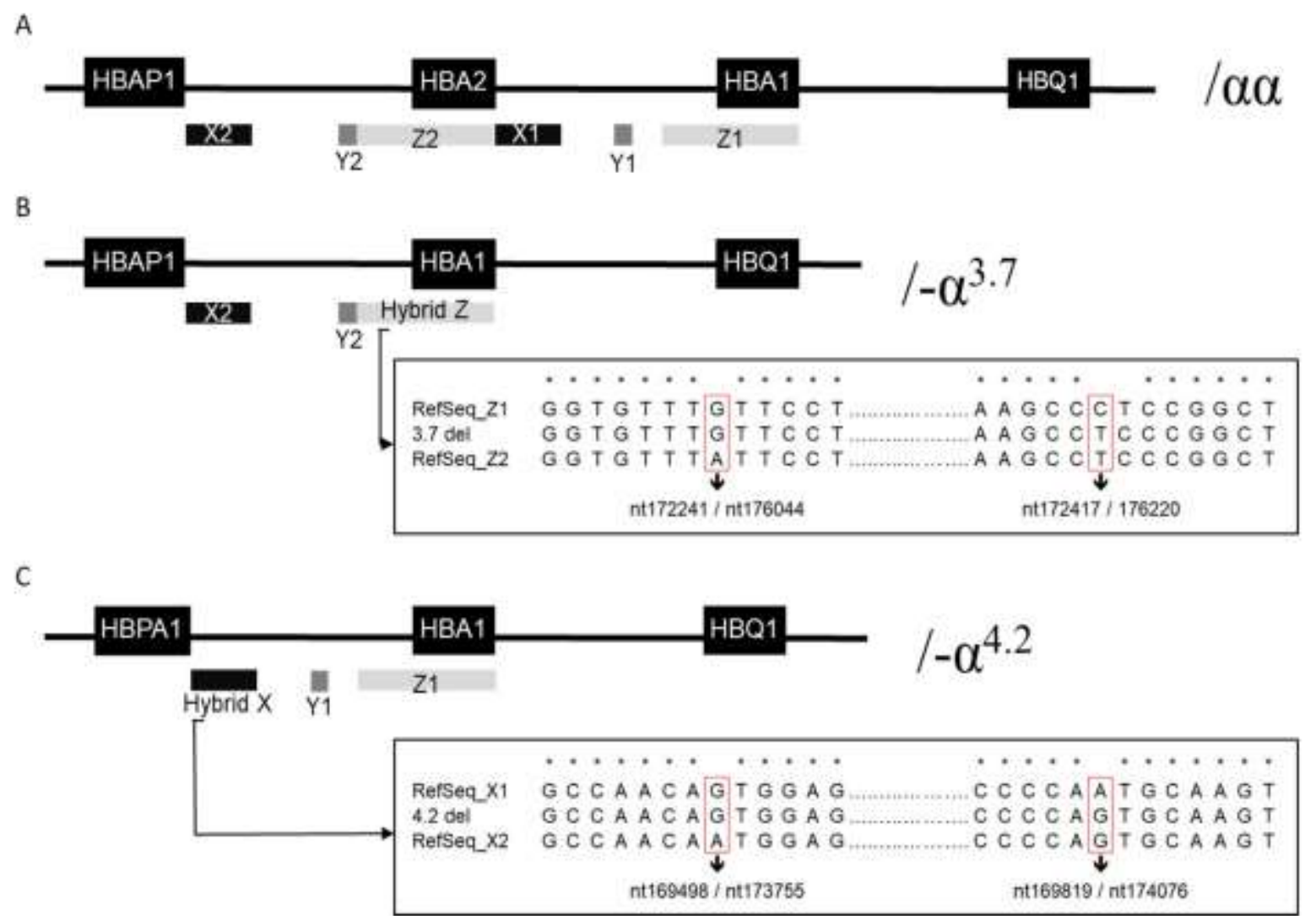

Fig. 3. (A) The normal alpha globin gene cluster with $X, Y$, and $Z$ homology boxes. (B) The alpha globin cluster of the $\alpha 3.7$ allele with the sequence alignment of hybrid $\mathrm{Z}$ box. (C) The alpha globin cluster of the $-\alpha 4.2$ allele with the sequence alignment of hybrid $\mathrm{X}$ box.

Table 3. Hematological comparison of alpha-thalassemia trait based on its genotypes.

\begin{tabular}{|c|c|c|c|c|c|}
\hline \multirow{3}{*}{ Parameter } & \multicolumn{4}{|c|}{ Genotypes group* } & \multirow{3}{*}{$\mathbf{p}^{*}$} \\
\hline & \multicolumn{2}{|c|}{ Silent trait $(n=11)$} & \multicolumn{2}{|c|}{ Trait $(n=6)$} & \\
\hline & Range & Mean \pm SD & Range & Mean \pm SD & \\
\hline $\mathrm{Hb}(\mathrm{g} / \mathrm{dL})$ & $7.5-15.9$ & $12.61 \pm 2.14$ & $9.7-13.4$ & $11.42 \pm 1.25$ & $\mathrm{p}=0.08$ \\
\hline MCV (fL) & $67.5-79.9$ & $75.69 \pm 3.62$ & $59.1-74.5$ & $66.8 \pm 6.90$ & $\mathrm{p}=0.01$ \\
\hline $\mathrm{MCH}(\mathrm{pg})$ & $21.4-26.1$ & $24.31 \pm 2.01$ & $18.4-23.4$ & $21.18 \pm 1.79$ & $\mathrm{p}=0.003$ \\
\hline
\end{tabular}

*p-value of Student's t-test for independent samples

\section{Discussion}

alpha-Thalassemia is a recessive disorder with a symptomless carrier which can be identified by a haematological analysis. Carriers are associated with reduced $\mathrm{MCH}$ and $\mathrm{MCV}$. Their diagnosis is based on microcytosis $(\mathrm{MCV}<80$ $\mathrm{fL}, \mathrm{MCH}<27 \mathrm{pg}$ ) and normal HbA2 level (< $3.5 \%$ ) distinguishing them from $\beta$-thalassemia carriers (9). However, haemoglobin parameter is rarely used to determine the alpha-
Thalassemia silent trait because subjects with only one mutated gene usually have a normal haemoglobin level, while those with two altered gene ( $\alpha$ - thalassemia trait) have slightly reduced haemoglobin level causing mild anaemia $(10,11)$.

Present study reported 3.7-kb deletion as most common deletion. This result was similar to a study conducted in Jakarta showing 58\% prevalence in alpha-Thalassemia patients (12). 
This finding revealed the importance of detecting the $3.7-\mathrm{kb}$ deletion in future thalassemia screening. In addition, we also identified carrier with double heterozygous of $\alpha^{3.7} /-\alpha^{4.2}$ which has not been discovered before.

The alpha-Thalassemia trait with SEA deletion is the main cause of $\mathrm{HbH}$ disease and $\mathrm{Hb}$ Bart's hydrops fetalis cases in Southeast Asia $(2,13)$. Determining the breakpoint is important to develop a reliable method to detect mutation as early as possible. Our study presents a clear chromatogram in which the SEA deletion breakpoint was located (Fig. 2A). Although the chromatogram was similar to a study reported in Mexico, the description of the precise site of the 5' breakpoint differed. The Mexican study located the $5^{\prime}$ breakpoint in the HBM sequences at cd28 (14), while our alignment located it between HBZP1 and HBM which was 191-bp after the end of the HBZP1 sequence precisely at nt165396 (Fig. 2B). In addition, we provided 5' and 3 ' boundary sites along with their relative distance to the nearest gene and nucleotide position on chromosome 16 .

The boundary sites of the $3.7-\mathrm{kb}$ and $4.2-\mathrm{kb}$ deletions were determined in the $\mathrm{Z}$ and $\mathrm{X}$ boxes of the alpha-globin cluster respectively, while their precise breakpoint varied (15-17). A precise breakpoint could contribute on establishing a rapid and reliable detection method. One of the methods is qPCR, which is superior due to its speed, sensitivity, and reproducibility. Furthermore, It does not require any post-PCR treatment (18). However, the amplicon size for qPCR should not exceed 200bp so that the primer location should be close to the breakpoint site. Using the finding of this study, a qPCR strategy for $-\alpha^{3.7}$ and $-\alpha^{4.2}$ alleles can be designed by utilizing the sites of breakpoint region (Figs. 3B and 3C).

The $-\alpha^{3.7}$ allele caused by the $3.7-\mathrm{kb}$ deletion is divided into three haplotypes of $-\alpha^{3.7 I},-\alpha^{3.7 I I}$, and $-\alpha^{3.7 I I I}(2)$. The allele found in this study was $-\alpha^{3.71}$ because the alpha-globin genes did not merge (19). Others study have analysed $-\alpha^{3.7 I}$ and $-a^{3.7 I I}$ which were caused by misalignment within the alpha-globin gene resulting in the formation of hybrid HBA2-1, a merger of HBA1 and HBA2 genes (16).
The haematological parameters for each genotype of alpha-Thalassemia trait were well presented in a study of Iranian population with 722 samples which included MCH, MCV, mean corpuscular haemoglobin concentration (MCHC), and haemoglobin (10). It reported that MCV and MCH levels between silent trait and trait differed significantly $(\mathrm{p}<0.001)$, whereas our comparison showed a significant result only in $\mathrm{MCH}(\mathrm{p}<0.003)$. The MCH data shows a consistent and significant difference with big and small numbers of samples. Therefore, it is more reliable for predicting whether the sample was silent trait or trait thalassemia than with other parameters.

Our study has at least two potential limitations, First, we only focused on the haematological characteristic from the routine blood count specifically haemoglobin, $\mathrm{MCV}$ and $\mathrm{MCH}$. Other parameter that could be added are $\mathrm{Hb}$ electrophoresis which could unravel the coinheritance of $\alpha$ - and $\beta$-thalassemia carrier (20), serum ferritin level to investigate the existence of iron deficiency anaemia (21), and adipokine levels which may indicate the development of inflammation-induced complications related the disease severity (22). Second, we did not collect ethnic information from the volunteers thus we cannot dispute whether the genotypes we found in this study correlated with any particular ethnicity. Some past studies have reported SEA, 3.7- $\mathrm{kb}$ and 4.2-kb deletions in Javanese ethnicity (12,23), 3.7-kb deletion in Gayo, Sumba, and Ternate populations, and SEA deletion in the Gayo population (5). Although the Yogyakarta Special Region is located on the island of Java, the majority of which are Javanese ethnicity, there is still a possibility that volunteers will come from diverse ethnicities. Learning from this, we strongly recommend for future related studies to retrieve ethnic information for a better understanding of genotype prevalence of alpha thalassemia in the region.

In summary, our study concluded that SEA, $3.7-\mathrm{kb}$ and $4.2-\mathrm{kb}$ deletions were found in Yogyakarta Special Region with the most prevalence was 3.7-kb deletion. The respective molecular and haematological features have been characterized. The findings in this study 
were significant to provide insight on developing rapid detection technique and direction for future thalassemia screening strategy.

\section{Acknowledgements}

Authors would like to express gratitude to Indonesian Association of Parents of Children with Thalassemia (APCT) Yogyakarta and the

\section{References}

1. Higgs DR, Vickers MA, Wilkie AO, Pretorius IM, Jarman AP, Weatherall DJ. A review of the molecular genetics of the human alpha globin gene cluster. Blood. 1989;73(5):1081-104.

2. Harteveld CL, Higgs DR. $\alpha$-thalassaemia. Orphanet Journal of Rare Diseases. 2010;5:13.

3. Goh LPW, Chong ETJ, Lee PC. Prevalence of alpha $(\alpha)$-thalassemia in Southeast Asia (20102020): A meta-analysis involving 83,674 subjects. Int $\mathbf{J}$ Environ Res Public Health. 2020;17(20):7354.

4. Husna N, Arif A Al, Putri C, Leonard E, Handayani NSN. Prevalence and Distribution of Thalassemia Trait Screening. J thee Med Sci (Berkala Ilmu Kedokteran). 2017;49(03):106-13. 5. Nurfitriani R, Abinawanto A, Noviyanti R, Trianti L, Nainggolan IM. Detection of Papua New Guinea Thalassemia Alpha Mutation in Gayo, Sumba, Ternate, and Timika Populations. Makara J Sci. 2014;18(2).

6. Maharani EA, Soedarmono YSM, Nainggolan IM. Frequency of thalassemia carrier and $\mathrm{Hb}$ variant and the quality of stored donor blood. Medical Journal of Indonesia. 2014;23(4):209.

7. Widyastiti NS, Nainggolan IM, Kurnia EL, Retnoningrum D, Budiwiyono I. A rare case of $\mathrm{Hb} \mathrm{H}$ disease caused by compound heterozygous for $\alpha$ thalasemia and $\mathrm{Hb}$ Quong Sze in Chinese Indonesian proband: a case report. Bali Med J. 2019;8(2):425.

8. Chong SS, Boehm CD, Higgs DR, Cutting GR. Single-tube multiplex-PCR screen for common deletional determinants of $\alpha$ thalassemia. Blood. 2000;95(1):360-2.

9. Singer ST. Variable clinical phenotypes of $\alpha-$ thalassemia syndromes. ScientificWorldJournal. 2009;9:615-25.
Indonesia Thalassemia Foundation (ITF) for conducting the screening and valuable assistant. This study was financially supported by Ministry of Research and Technology of the Republic of Indonesia Indonesia for NSNH with the grant number 23/UN1/DITLIT/DITLIT/LT/2018.

All of the authors declare that there are no conflicts of interests.

10. Akhavan-Niaki H, Youssefi Kamangari R, Banihashemi A, Kholghi Oskooei V, Azizi M, Tamaddoni A, et al. Hematologic features of alpha thalassemia carriers. Int $\mathbf{J}$ Mol Cell Med. 2012;1(3):162-7.

11. Borges E, Wenning MRSC, Kimura EM, Gervásio SA, Costa FF, Sonati MF. High prevalence of $\alpha$-thalassemia among individuals with microcytosis and hypochromia without anemia. Braz J Med Biol Res. 2001;34(6):759-62. 12. Setianingsih I, Harahap A, Nainggolan IM. Alpha thalassaemia in Indonesia: Phenotypes and molecular defects. Adv Exp Med Biol. 2003;531:47-56.

13. Weatherall DJ, Clegg JB. Inherited haemoglobin disorders: An increasing global health problem. Bull World Health Organ. 2001;79(8):704-712.

14. Nava MP, Trejo JM, Aguilar-Luna C, BarrosNúñez P, de la Luz Chávez M, Magaña MT, et al. Molecular characterization of the - SEA alpha thalassemia allele in Mexican patients with $\mathrm{HbH}$ disease. Rev Investig Clin. 2006;58(4):313-7.

15. Ou-Yang H, Hua L, Mo QH, Xu XM. Rapid, accurate genotyping of the common $-\alpha 4.2$ thalassaemia deletion based on the use of denaturing HPLC. J Clin Pathol. 2004;57(2):15963.

16. Chow A, Ghassemifar R, Finlayson J. Alpha thalassaemia due to non-deletional mutations on the -3.7 alpha globin fusion gene: laboratory diagnosis and clinical importance. Pathology. 2013 Oct;45(6):591-4.

17. Hung CC, Lee CN, Chen CP, Jong YJ, Hsieh WS, Lin WL, et al. Molecular assay of $-\alpha 3.7$ and $-\alpha 4.2$ deletions causing $\alpha$-thalassemia by denaturing high-performance liquid 
chromatography. Clin Biochem. 2007;40(11):817-21.

18. Gaafar T, ELBeshlawy A, Aziz M, Abdelrazik H. Rapid screening of $\beta$-Globin gene mutations by Real-Time PCR in Egyptian thalassemic children. African Journal of Health Sciences. 2008;13(3):70-7.

19. Higgs DR. The Molecular Basis of aThalassemia. Cold Spring Harb Perspect Med. 2013;3(1):a011700.

20. Sahiratmadja E, Seu MMV, Nainggolan IM, Mose JC, Panigoro R. Challenges in thalassemia carrier detection in a low resource setting area of eastern Indonesia: The use of erythrocyte indices. Mediterr J Hematol Infect Dis. 2021;13(1):e2021003.
21. Chen M, Huang H, Chen L, Lin N, Zhang M, Lin Y, et al. First report of the spectrum of $\delta$ globin gene mutations among women of reproductive age in Fujian area-Discrimination of $\delta$-thalassemia, $\alpha$-thalassemia, and Iron Deficiency Anemia. J Clin Lab Anal. 2020;34(11):e23479.

22. Sattar Harbi N, Hussein Jawad A, Kadhum Alsalman F. Evaluation of Adipokines Concentration in Iraqi Patients with Major and Minor Beta Thalassemia. Reports Biochem Mol Biol. 2020;9(2):209-215.

23. Nainggolan IM, Harahap A, Ambarwati DD, Liliani R V, Megawati D, Swastika M, et al. Interaction of $\mathrm{Hb}$ Adana (HBA2: C.179G $>\mathrm{A}$ ) with deletional and nondeletional $\alpha+$-thalassemia mutations: Diverse hematological and clinical features. Hemoglobin. 2013;37(3):297-305. 